\title{
Dyslexia and ICTs, Assessment and Early Intervention in Kindergarten
}

\author{
http://dx.doi.org/10.3991/ijet.v11i02.5193
}

\author{
Athanasios S. Drigas and Batziaka Elektra \\ N.C.S.R. 'Demokritos', Inst. of Informatics and Telecommunications, Telecoms Lab - Net Media Lab, Athens, Greece
}

\begin{abstract}
This article is a review of how Information and Communication Technologies (ICTs) help in the assessment and early intervention of reading disabilities (RD) and especially of dyslexia. Phonological awareness is highlighted as a main ability that predicts later reading skills. Here are presented several studies that display computer games, programs and applications by which teachers can intervene to boost phonological awareness and help preventing RD or dyslexia from an early age. Most studies focus in preschool age, although dyslexia in kindergarten is a field that has not been investigated thoroughly, and are certainly a precursor for studies to follow.
\end{abstract}

Index Terms-ICTs, reading disabilities, dyslexia, phonological awareness, early intervention, games.

\section{INTRODUCTION}

According to the National Institute of Neurological Disorders and Stroke, RD or dyslexia is a brain-based type of learning disabilities that strictly weakens a person's ability to read [1]. Dyslexia is not related with a person's IQ but, as shown in the studies discussed later, it has strong connection with phonological awareness, short term memory and rapid naming.

Among different countries and theoretical views differences are detected in the use of terms for dyslexia. These terms usually reflect different research techniques [2] and ethnic policies about education. In many countries children struggling with RD attend general school but have special educational needs. Thus, early diagnose, appreciation of these special needs and intervention can help the educational process, in respect of children and teachers.

ICTs are a growing field which is gradually becoming established as a means of supporting education [2], especially where special educational needs are present.

This article is a review of how Information and Communication Technologies help in the assessment and early intervention of RD and especially of dyslexia. Here are presented several studies that include computer games, programs and applications that can boost phonological awareness or help preventing reading disabilities and dyslexia.

Emphasis is given in phonological awareness, as it proves to be one of the most crucial predictors of future reading problems. Techniques, computer programs, applications and games are reported and the significance of ICTs and how they can help in education is highlighted, especially on children diagnosed with RD, through the citation of studies and experiments. The vital role of early intervention and preschool age as a nodal point for assessment and intervention of dyslexia is revealed [3], [4].

\section{Phonological Awareness And ICTS}

Phonological awareness refers to the ability of someone to recognize that every sentence can break down into syllables, every syllable can break down into words and every word can break down into phonemes [5]. It is a very important capability and, at the same time, a reliable predictor of children's later ability to read [6]. "Phonological awareness, as with other decoding skills, is not an intuitive or naturally developing ability, as language skills may be for some children, but rather may require deliberate teaching and practice opportunities" (p.4) [6]. As it seems, it is significant that preschool education, through appropriate activities, reinforce phonological awareness of students so that their later reading ability will be strengthened.

Under the Treaty of Salamanca all children should learn together regardless of any differences [7]. That includes children with reading difficulties, who are part of the regular school. Thus, it is the teacher's liability to find ways to include these children in the educational process.

It is especially substantial that teachers find ways to boost phonological awareness in children whose development of literacy and phonological awareness falls short of their age. It is important that teachers remember the significance of feedback. "This means that newly introduced skills, concepts, and vocabulary need to be repeated and revisited as a natural occurrence not just throughout the day but as planned, ongoing cycle throughout the year" (p.9) [6].

As said before, one of the most effective ways to prevent $\mathrm{RD}$ in the future is to strengthen phonological awareness in early years. In this, using technology may help, as it has established positive results in supporting students with special needs during the last decades [8].

Specially constructed computer programs can help children with RD to develop literacy through a playful and guided way. In accordance with Barker and Torgesen; Mioduser, Tur-Kaspa, and Leitner; Reitsma and Wesseing, cited in Segers \& Verhoeven, studies have shown that computer intervention can strengthen phonological awareness in both children who are at risk of reading disorders and children who are not [9].

Segers and Verhoeven (2004) designed specific training computer-based exercises and researched if they can increase phonological awareness in kindergarten children struggling with RD, who worked with the computer program for 14 times, 15 minutes each time. The program included computer exercises for word awareness, syllabic awareness, rhyme awareness and phonemic awareness. 
The results showed substantial progress made in these areas after the intervention program [9].

According to Moody (2010) electronic books are also a fun and effective way to enhance kindergartner's phonological awareness. She supports that e-story books can develop children's literacy skills, reinforce independent reading, demonstrate word pronunciation, prevent children from losing interest - because of their digital features - and provide instant feedback [10].

Haugland and Wright, cited in Van Scoter [8], state that children tend to take leadership roles and interact more with a computer program. Van Scoter (2008) supports that computer programs can help children reinforce their skills in literacy and that technology can offer main assistance to students with special needs. Nevertheless, for technology to be a cofactor that can enhance phonological awareness in kindergartners, it must follow and supplement the curriculum, always with the teacher as guide, and be applied in daily routine [8].

\section{ASSESSMENT AND ICTS}

According to Philips et al. (2008) assessment is a really vital factor for all children in every educational stage and it is necessary in preschool age, as it can prevent future reading problems [6]. It is the best way to see the child's abilities or weaknesses as kindergarten children are not "tabula rasa". "Therefore, a teachers initial task is to use formal or informal assessment to identify where each child is showing mastery" (p. 5) [6]. Toki, Pange and Mikropoulos (2012) also stress the importance of teachers in the assessment of reading disorders, which is crucial for an early intervention to follow [11].

Justice, Invernizzi, \& Meier (2002) support that literacy screening at early age offers a strong means for prevention and later intervention, if needed, since not every child battling with deficiency in communication will face literacy problems. According to the same authors, screening tools should be used to examine children's skills in the fields of written language awareness, phonological awareness, letter name knowledge, grapheme-phoneme correspondence, literacy motivation and home literacy, which can predict extensively literacy achievement. It is worth mentioning that screening tools should be designed and tested by experts, for a certain group of students and should be combined with intervention and assessment tools for better results [12].

Snow, Burns and Griffin (as cited at Pennington \& Lefly) [13] accentuate the importance of early classification and intervention of children at risk for reading disorders. According to Pennington and Lefly (2001) assessment should be made at early age, as the risk of dyslexia is likely to be inherited [13].

Schatschneider, Fletcher, Francis, Carlson, and Foorman (2004) support, after studies, that assessment should be made in phonological awareness, letter sound knowledge and Rapid Automized Naming, as they are factors that can strongly predict future reading problems, as early as the stage of kindergarten [14]. Likewise, according to Sutherland and Gillon (2005) intervention on phonological awareness should take place at an early age, but before that an appropriate assessment is fundamental [15].

Toki et al. (2012) underline that ICTs, through appropriate programs (like APLo), can give an accurate evalua- tion of a child's reading disorders [11]. Singleton, Thomas, and Horne (2000) highlighted the advantages of computer based assessment which, as they said, is more enlightening and it gives results faster. They made a longitudinal study in 421 children and presumed that short term memory and phonological awareness can predict the ability of a student to read [16].

Aristodemou, E., Taraszow, T., Laouris, Y., Papadopoulos, T., Makris (n.d.) developed a nonverbal screening test named MAPS (Mental Attributes Profiling System) that can assess the learning capacities of students at any age. The test evaluates different learning aspects, such as lateral awareness, the ability to categorize, visual and auditory memory, visual and auditory discrimination, sequencing and navigation. After the implementation it was found that lateralization, auditory memory, categorization, sequencing and auditory discrimination are the five greatest predictors of reading performance [17].

\section{EARLY INTERVENTION AND ICTS}

A kindergarten child cannot be diagnosed with dyslexia because of its early age. What should be done, though, is to discover if it has specific language impairment (SLI) or other language difficulties that can lead to dyslexia in the future. In that case immediate intervention is needed, especially in the field of phonological awareness [18], children's auditory and speech processing, regarding their close relationship with reading development and dyslexia [3].

Elbro, Borstrøm, and Petersen (1998) had early highlighted the importance of prediction and prevention of reading disabilities since they believe that language skills in preschool age adjust future reading development. After a study they made in kindergarten children, they confirm that, except phonological awareness, naming speed and short term memory, the quality of phonological representations is also a crucial factor that can predict reading difficulties [4].

Macaruso and Walker (2008) presented a 6-month computer intervention in phonological awareness of kindergartners. The results showed that children can benefit of such programs which are easy and fun to use and give immediate feedback [19].

Wolgemuth et al. (2013) confirmed that programs using ICT can help teachers boost literacy skills in their early aged students. He and his team applied an intervention program named ABRA (ABRACADABRA) with the help of specially educated teachers, using school's existing technology. Before the execution of ABRA the level of early reading ability, early literacy skills and reading and math skills of each child who participated was assessed through computer-based or not tools (such as GRADE K, PIPS-BLA and APFOR). The results showed that, after the implementation of ABRA, phonological awareness and phoneme-grapheme correspondence of all students was improved and the effects on indigenous student's early literacy skills were encouraging [20].

Shamir \& Korat (2007) developed and implemented an educational e-book that intended to foster kindergartener's emergent literacy through activities that children would find amusing. Children participated in three e-book activities: "read only", "read with dictionary" and "read and play". The results showed pure improvement in children's 
emergent literacy and writing, word recognition, and phonological awareness [21].

Segers and Bosman (2013) made a 3-weeks computer intervention at first graders with SLI and found out that it was easier to teach children with normal non-verbal IQ than children with lower non-verbal IQ. That indicates the importance of assessing and intervening in, not only phonological awareness, but also other aspects of IQ, in order to prevent learning disabilities [18].

\section{GAMES AND DYSLEXIA}

The term gamification refers to integration of some characteristics of games in real life situations intended to change the user's way of thinking and acting, so that he or she is more involved in solving problems [22]. As said by Eriksson, Musialik and Wagner (2012), games strengthen children's confidence and help them feel more powerful as they learn to cooperate, realize their mistakes and make what pictures unmanageable, achievable [22]. They also help users imagine and compose virtual societies so that they can interact more with people in real life and enhance the feeling of belonging. All these factors are considered when creating a game that will help children with reading disabilities [22]. Eriksson et al. (2012) cite that games and applications can adjust to education making it a fun and learning experience [22]. Thus gamification is a way to engage students in curriculum activities.

Richardson and Lyytinen (2014) presented the results of the adjustment of "GraphoGame", a game designed to help kindergarteners showing early signs of dyslexia to recognize and separate phonemic sounds. Richardson and Lyytinen (2014) mention that the game is simple and accessible and it gives immediate feedback and rewards. The results were positive for letter knowledge and reading decoding skills of the children who played the game for a specific period of time [23].

According to Stanovich (1988) and Ziegler (2006), cited in Richardson \& Lyytinen [23] a dyslexic student cannot manage phonological features and thus he or she is having trouble in sound managing written language. The GraphoGame method concentrates in this, i.e. in teaching sound decoding [23].

\section{DISCUSSION}

The purpose of this article was to stress the importance of early assessment and intervention of RD and to examine if ICTs can be a booster in this process, according to contemporary bibliography.

Studies reviewed tend to point out that phonological awareness seems to be the most critical predictor of a child's later reading facilities and that future reading development depends on language skills in preschool age [4], [6], [18]. Several studies concentrated on how teachers can screen and strengthen literacy skills and phonological awareness of their students as early as the age of kindergarten [12], [21].

Most studies agree that ICT can have a positive effect on students learning development and can offer a valuable tool, strengthening the educational process especially in students with special needs. A number of assessment and intervention tools has been presented, such as games [23] and computer programs [11], [17], [20], [21], aiming at evaluating and reinforcing children's emerging literacy, phonological awareness, and learning capacities. It turns out that computer-based tools benefit both students and teachers. They are an easy and fun way for children to learn [22], give immediate feedback [23] and facilitate teacher's job, since children can work on their own, without the constant presence of the educator and give faster results.

However there are several fields that demand additional research, as reading disorders in preschool age is a sector that hasn't been investigated thoroughly. So far researchers tend to focus on school age students, understating the importance of preschool abilities. Nevertheless, the results of the investigations that have been accomplished to date indicate that assessment and intervention at preschool age is a nodal point for later prevention of a child's weaknesses and enhancement of its capabilities.

Besides the scarcity of researches in this particular field and the reduced interest up to the present time, results are encouraging and indicate that ICTs contribute positively in the assessment and intervention of reading disabilities in early age.

\section{REFERENCES}

[1] National Institute of Neurological Disorders and Stroke. (2011). NINDS Dyslexia Information Page. Retrieved from http://www.ninds.nih.gov/disorders/dyslexia/dyslexia.htm

[2] Drigas, A. S., \& Ioannidou, R. (2013). Special Education and ICTs. International Journal of Emerging Technologies, 8(2), 4147. http://dx.doi.org/10.3991/ijet.v8i2.2514

[3] Boets, B., Vandermosten, M., Poelmans, H., Luts, H., Wouters, J., \& Ghesquière, P. (2011). Preschool impairments in auditory processing and speech perception uniquely predict future reading problems. Research in Developmental Disabilities, 32(2), 560-70. http://dx.doi.org/10.1016/j.ridd.2010.12.020

[4] Elbro, C., Borstrøm, I., \& Petersen, D. (1998). Predicting dyslexia from kindergarten: The importance of distinctness of phonological representations of lexical items. Reading Research Quarterly, 33(1), 36-60. http://dx.doi.org/10.1598/RRQ.33.1.3

[5] Brummit-Yale, J. (n.d.). Phonemic Awareness vs. Phonological Awareness. Retrieved from http://www.k12reader.com/phonemicawareness-vs-phonological-awareness

[6] Philips, B. M., Clancy-Menchetti, J., Lonigan, C. J. (2008). Lessons from the classroom. Special Education, 28(1), 3-17. http://dx.doi.org/10.1177/0271121407313813

[7] United Nations Educational, Scientific and Cultural Organization \& Ministry of Education and Science, Spain (1994). The Salamanca Statement and Framework for Action on Special Needs Education (ED-94/WS/18). Retrieved from http://www.unesco.org/education/pdf/SALAMA E.PDF

[8] Scoter, J. Van. (2008). The potential of IT to foster literacy development in kindergarten. In J. Voogt \& G. Knezek (Eds.), International Handbook of Information Technology in Primary and Secondary Education (pp. 149-161). Springer. Retrieved from http://link.springer.com/chapter/10.1007/978-0-387-73315-9_9 http://dx.doi.org/10.1007/978-0-387-73315-9_9

[9] Segers, E., \& Verhoeven, L. (2004). Computer-supported phonological awareness intervention for kindergarten children with specific language impairement. Language, Speech, and Hearing Services in Schools, 35(3), 229-239. http://dx.doi.org/10.1044/0161-1461(2004/022)

[10] Moody, A. (2010). Using electronic books in the classroom to enhance emergent literacy skills in young children. Journal of Literacy and Technology, 11(4), 22-52. Retrieved from http://people.cs.vt.edu/ shaffer/cs6604/Papers/Elearningin_Classr ooms Moody.pdf

[11] Toki, E. I., Pange, J., \& Mikropoulos, T. a. (2012). An Online Expert System for Diagnostic Assessment Procedures on Young Children's Oral Speech and Language. In Procedia Computer Science (Vol. 14, pp. 428-437). http://dx.doi.org/10.1016/j.procs .2012 .10 .049 
[12] Justice, L. M., Invernizzi, M. A., \& Meier, J. D. (2002). Designing and Implementing an Early Literacy Screening Protocol. Language Speech and Hearing Services in Schools, 33(2), $84-$ 101. http://dx.doi.org/10.1044/0161-1461(2002/007)

[13] Pennington, B. F., \& Lefly, D. L. (2001). Early Reading Development in Children at Family Risk for Dyslexia. Child Development, 73(3), 816-833. http://dx.doi.org/10.1111/14678624.00317

[14] Schatschneider, C., Fletcher, J. M., Francis, D. J., Carlson, C. D., \& Foorman, B. R. (2004). Kindergarten Prediction of Reading Skills: A Longitudinal Comparative Analysis. Journal of Educational Psychology, 96(2), 265-282. http://dx.doi.org/10.1037/0022-0663.96.2.265

[15] Sutherland, D., \& Gillon, G. T. (2005). Assessment of phonological representations in children with speech impairment. Language, Speech, and Hearing Services in Schools, 36(4), 294307. http://dx.doi.org/10.1044/0161-1461(2005/030)

[16] Singleton, C., Thomas, K., \& Horne, J. (2000). Computer-based cognitive assessment and the development of reading. Journal of Research in Reading, 23(2), 158-180. http://dx.doi.org/10.1111/ 1467-9817.00112

[17] Aristodemou, E., Taraszow, T., Laouris, Y., Papadopoulos, T., Makris, P. (n.d.). Prediction of Reading Performance Using the MAPS (Mental Attributes Profiling System) Multimodal Interactive ICT Application. Retrieved October 09, 2014, from http://www.cyberethics.info/cyethics1/images/stories/pdf/ECEL08 PredictionReadingPerformanceWithMAPS_AristodemouEtAl_re vised.pdf

[18] Segers, E., \& Bosman, A. M. T. (2013). Early Literacy Interventions Using ICT in Children with SLI. In A. Shamir \& O. Korat (Eds.), Technology as a Support for Literacy Achievements for Children at Risk (pp. 187-197). Dordrecht: Springer Netherlands. http://dx.doi.org/10.1007/978-94-007-5119-4

[19] Macaruso, P., \& Walker, A. (2008). The Efficacy of ComputerAssisted Instruction for Advancing Literacy Skills in Kindergarten Children. Reading Psychology, 29(3), 266-287. http://dx.doi.org/10.1080/02702710801982019

[20] Wolgemuth, J. R., Savage, R., Helmer, J., Harper, H., Lea, T., Abrami, P. C., ... Louden, W. (2013). ABRACADABRA aids Indigenous and non-Indigenous early literacy in Australia: Evidence from a multisite randomized controlled trial. Computers \& Education, 67, 250-264. http://dx.doi.org/10.1016/j.compedu. 2013.04.002
[21] Shamir, A., \& Korat, O. (2007). Developing an Educational EBook for Fostering Kindergarten Children's Emergent Literacy Developing an Educational E-Book for Fostering Kindergarten Children' $\mathrm{s}$ Emergent Literacy. Computers in the Schools: Interdisciplinary Journal of Practice, Theory, and Appied Research, 24(1-2), 125-143. http://dx.doi.org/10.1300/J02 5v24n01 09

[22] Eriksson, B., Musialik, M., \& Wagner, J. (2012). GamificationEngaging the Future. Retrieved from https:/gupea.ub.gu.se/ handle/2077/30037

[23] Richardson, U., \& Lyytinen, H. (2014). The GraphoGame method: The theoretical and methodological background of the technologyenhanced learning environment for learning to read. Human Technology, 10(1), 39-60. Retrieved from http://www.humantech nology.jyu.fi/articles/volume10/2014/Richardson_Lyytinen.pdf http://dx.doi.org/10.17011/ht/urn.201405281859

\section{AUTHORS}

Athanasios Drigas is a Research Director at IITN.C.S.R. Demokritos. He is the Coordinator of Telecoms Lab and founder of Net Media Lab since 1996. From 1985 to 1999 he was the Operational manager of the Greek Academic network. He has been the Coordinator of Several International Projects, in the fields of ICTs, and eservices (e-learning, e-psychology, e-government, einclusion, e-culture etc). He has published more than 270 articles, 7 books, 25 educational CD-ROMs and several patents. He has been a member of several International committees for the design and coordination of Network and ICT activities and of international conferences and journals. (e-mail: dr@iit.demokritos.gr).

Electra Batziaka graduated in 2006 from Early Childhood Education department of University of Thessaly. While working as a preschool age teacher at the public educational system of Greece, she continued her training with Special Education and ICT's seminar at N.C.S.R. Demokritos. Since 2014 she is a scientific cooperator of Net Media Lab. (e-mail: ebatziaka@yahoo.com).

Submitted 05 November 2015. Published as resubmitted by the authors 28 January 2016. 